\title{
A Missa Grande de Antônio dos Santos Cunha: influências operísticas na obra de um compositor colonial mineiro
}

\author{
Edílson Rocha (UFBA) \\ ediassuncao@hotmail.com
}

Resumo: Este artigo faz um breve apanhado sobre o pouco que se sabe até o momento a respeito do compositor da Escola Mineira do final do século XVIII, Antônio dos Santos Cunha. Faz uma descrição física dos originais consultados da obra Missa Grande e procura identificar elementos de escrita operística presentes em vários pontos da composição. Também descreve dados curiosos e pitorescos que puderam ser descobertos a partir do estudo das partituras remanescentes. Palavras-chave: musicologia; Antônio dos Santos Cunha; música colonial mineira; compositor; biografia; regência.

Missa Grande by Antônio dos Santos Cunha: operistic influences in the work of a colonial Brazilian "mineiro" composer

Abstract: This paper discloses a brief collection of notes about Brazilian composer Antônio dos Santos Cunha, from the late eighteenth-century Minas Gerais School. It describes the original scores of his masterpiece called Missa Grande and tries to identify operatic influences in several excerpts of the composition. This paper also presents anecdotal facts based on the study of the remaining scores.

Keywords: musicology; Antônio dos Santos Cunha; Brazilian colonial music; composer; biography; conducting

\section{1- Objetivos}

Este artigo tem por finalidade divulgar a obra de Antônio dos Santos Cunha, cujo repertório, apesar de grande valor musical é praticamente desconhecido. A partir da análise da obra Missa Grande, busca reconhecer influências que possam ser decisivas para a identificação e reconhecimento de seu autor, bem como tenciona gerar informações úteis para sua interpretação e contribuir para o desenvolvimento de pesquisas musicológicas em torno do repertório colonial e histórico da cidade de São João del-Rei, MG.

\section{2- Introdução}

Muito pouco se sabe sobre Antônio dos Santos Cunha. Nos arquivos das orquestras de São João del-Rei, MG, existem apenas cinco obras deste compositor. São elas:

- Missa Grande

- Missa e Credo a Cinco Vozes

- Novenas de Nossa Senhora da Boa Morte

- Responsórios para Quarta, Quinta e Sexta Feira Santas

- Pange Língua a Baixo Solo (NEVES, 1982).

A rigor não se pode dizer que seja um compositor mineiro ou mesmo brasileiro. 0 caráter de sua obra evidencia uma sólida formação, que pode não ter sido adquirida em terras brasileiras. Existem alguns indícios de que seja português apesar de suas únicas obras conhecidas até o momento estarem em arquivos nacionais. José Maria Neves, ilustre musicólogo chegou a empreender pesquisa em Portugal, nas cidades de Évora e Coimbra. Segundo sua irmã Stella Neves, maestrina da Orquestra Ribeiro Bastos em São João del-Rei, nesta empreitada o pesquisador encontrou boa quantidade de músicos homônimos, "mais ou menos uns vinte". Em face de tal descoberta e da quantidade de dados que precisariam ser levantados, José Maria Neves desistiu e preferiu pesquisar Sigismund Neukomm (NEVES, 2004). Alguns indícios importantes levantam grande possibilidade de que fosse branco, e não negro ou mulato como a maioria dos músicos radicados na São João delRei setecentista (KIEFER, 1977). Existe anotação dando seu ingresso na Ordem Terceira do Carmo em 1800 bem como está registrado em livro de termos da Irmandade do Senhor Bom Jesus dos Passos, sua admissão como irmão em 1801. Estas associações somente aceitavam brancos e não há indícios de que tivesse renunciado à condição de homem de cor. Assim como os negros e mulatos, que encontravam na prática musical uma possibilidade de ascensão social numa época em que isto era muito raro, uma boa leva de portugueses também buscou as Minas Gerais de outrora à procura de trabalho e riqueza. Se Santos Cunha foi um destes não se sabe, mas uma anotação de 1815 o menciona como ausente para Lisboa (NEVES, 2000). Existe uma versão da Missa e Credo a 5 Vozes no cabido Metropolitano do Rio de Janeiro. 
Nesta versão, aparentemente autógrafa, apresenta uma dedicatória ofertada a D. Pedro I e em seu texto podese ler uma referência ao Dia do Fico, evento acontecido no ano de 1822. Do punho do próprio Santos Cunha, tal dedicatória só tem sua assinatura e uma breve reverência, o que indica que esteve na corte naqueles idos. É tudo que existe de informações concretas sobre o compositor.

Baseando-se nestes dados escassos, na análise de suas obras e em especulações ainda frágeis, calcula-se que tenha nascido por volta de 1775 e falecido em data posterior a 1822 (ROCHA, 2007).

Aloisio VIEGAS (2004) relata que falta até o presente momento pesquisa direcionada em documentações e arquivos. Se não for encontrada documentação cartorial, registro de bens ou anotações do gênero, poderá se tornar muito complicada a busca de informações, uma vez que restam para consulta apenas as anotações em documentação eclesiástica, muitas vezes incompletas. 0 próprio Aloísio Viegas narra que na Ordem do Carmo era hábito que os livros de entrada dessem o nome do ingressante, a filiação e o local de moradia. Sabendo disso, Viegas procurou por esta informação com muita esperança, uma vez que surgiriam daí mais informações, mas para decepção geral, estava faltando exatamente a folha em que deveriam constar os dados do compositor (VIEGAS, 2004).

\section{3- A Missa Grande}

Suas cópias estão no arquivo da Orquestra Ribeiro Bastos em São João del-Rei e foram encontradas empacotadas, amarradas com barbante junto a outras peças variadas e um recado que dizia "impossível de ser tocado" (NEVES, 2004). Trata-se de partituras avulsas, de partes instrumentais separadas, feitas por pelo menos sete copistas diferentes, provavelmente em épocas distintas. Apresentam sinais de intenso manuseio e algumas estão em péssimo estado de conservação. Muitas notas e compassos foram roídos por insetos nas cópias que parecem ser as mais antigas. Nenhuma das partes é autógrafa e estão encadernadas, separadas por instrumento e por vozes.

Apesar do nome pela qual a obra é conhecida, tratase de uma missa breve, em estilo clássico, que conta apenas com o Kyrie e o Gloria. Não apresenta o Quoniam tu solus, sendo que as cópias remanescentes o indicam "em cartina", ou seja, este trecho era para ser realizado a partir de cópia separada, não necessariamente do mesmo autor. As partes para contrabaixo e clarinete consultadas, por sua vez, apresentam uma linha melódica que seria correspondente ao Quoniam e indicam que seria para baixo solista. Os trechos se encontram na mesma tonalidade, Mi bemol maior, mas possuem quantidades de compassos muito diferentes. Levando-se se em conta que são cópias feitas por copistas diversos, é de se crer que não sejam composições de mesmo autor.

A Missa Grande apresenta a seguinte instrumentação original:

- Flauta

- Clarinetes I e II em Dó

- Trompas diatônicas I e II

- Violinos I e II

- Violas

- Baixo orquestral

- Coro misto a quatro vozes

- Soprano, contralto, tenor e baixo solistas.

É composta pelas seguintes partes

- Kyrie

- Gloria

- Laudamus (para soprano solo)

- Gratias

- Domine Deus (para terceto: soprano, tenor e baixo)

- Qui Tollis (para duo de soprano e contralto)

- Cum Sancto.

A obra tem como tonalidade principal o Ré maior e apresenta curiosidades, como uma evocação ao tema inicial da Marselhesa no Cum Sancto Spiritu. Existe um final alternativo na parte de flauta consultada e o Gratias aparentemente foi escrito para oito vozes. Existe anotado nas partes a indicação "a oito", mas só foram encontradas quatro partes vocais. Estas partes apresentam um tipo de escrita que pode parecer "soluçante", podendo talvez se tratar de acompanhamento para as outras vozes das quais ainda não se tem notícia. 0 Laudamus apresenta um solo de trompa, muito difícil de ser executado, pois emprega solos cromáticos numa época em que só existiam trompas diatônicas (Fig.1).

Para sua execução, o trompista tinha que colocar a mão dentro do instrumento para ajustar sua afinação, em passagens de agilidade. Apesar de ser uma obra em estilo clássico, apresenta um fugato no Cum Sancto Spiritu, que revela o domínio deste processo, relativamente raro na música colonial sanjoanense.

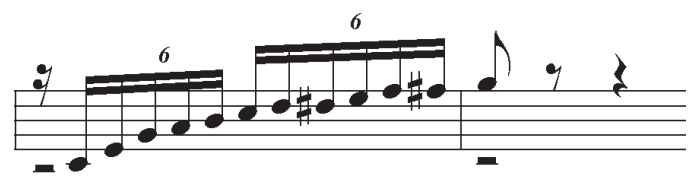

Fig.1: Trecho de parte do solo de trompa, em Fá, do Laudamus 


\section{4- Influência operística}

Pode-se perceber em uma detida análise das partituras de Antônio dos Santos Cunha que sua preocupação é mais musical do que litúrgica, o que poderia indicar um interesse preponderantemente musical. VIEGAS (2004) chama atenção para a prosódia do texto "in excelsis" no Gloria, cuja execução, caso não seja devidamente corrigida, pode soar como uma maria-fumaça. É interessante observar na Fig.2, que o autor emprega dois textos superpostos, o que sacrifica a clareza do texto em nome da dramaticidade.

Caso seja de fato português, Santos Cunha poderia durante sua formação ter sido exposto à avassaladora influência da ópera italiana, que foi muito popular em Portugal. Sabe-se inclusive que o compositor italiano Scarlatti (1685-1757) chegou a trabalhar para o rei (DIAS, 2002), tamanha a predileção pelos compositores da península itálica.
A Missa Grande deixa patente o gosto de seu compositor pelo bel canto. 0 Laudamus, para soprano solista, além do solo de trompa, apresenta uma linha melódica vocal que exige fôlego e bons recursos interpretativos. 0 andamento solicitado é o adágio, em compasso $2 / 4$, que ainda assim obriga o solista a alguma exibição de seus dotes vocais. Pode-ser ver na Fig.3 um pequeno trecho.

Pode-se observar que além de agilidade, a linha melódica exige grande extensão vocal, uma vez que chega ao Lá 2, altura não muito usual para o soprano. A Fig.4 mostra uma sugestão de cadência, onde o compositor obriga a intérprete a realizar quase duas oitavas, com indicação de dinâmica $f$ no grave. É possivel que as notas em fonte menor não sejam da lavra do autor, mas do copista.

A demonstração de virtuosismo prossegue pelos c.140150 (Fig.5), em um longo dueto entre o soprano solista e a trompa (em Fá).

$\mathrm{S}$

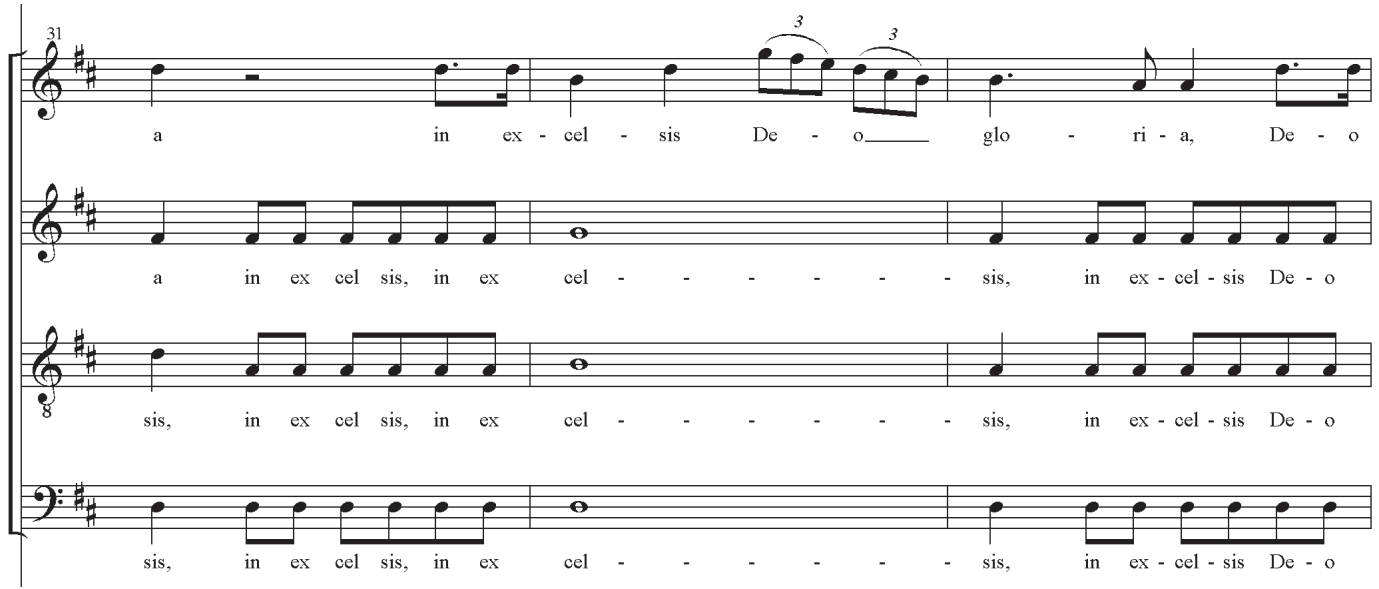

Fig.2: trecho coral do Gloria, com o texto in excelsis.

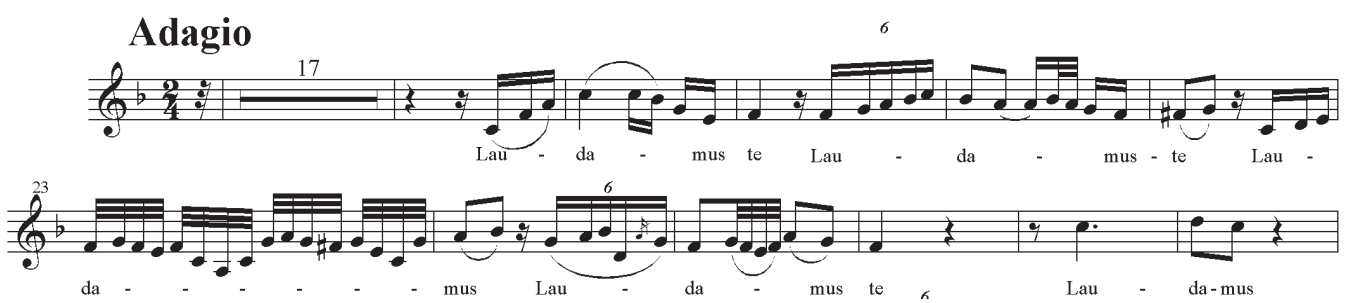

Fig.3: trecho do solo para soprano do Laudamus.

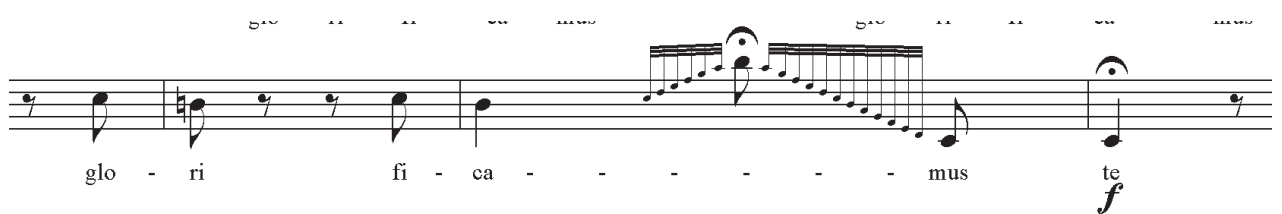

Fig.4: cadência para soprano solo, c.99-101. 
Pode-se ver também na Fig.6, uso de fusas, com um salto de sexta ascendente no c.160, e a chegada ao Lá agudo, clímax da frase e preparação para o final do trecho solista.

0 Domine Deus, um allegro escrito para soprano, tenor e baixo solistas, em compasso 4/4, apresenta recursos típicos de tercetos operísticos, onde cada uma das vozes se apresenta para depois cantarem juntas e em determinados momentos empregando o texto com prosódia desencontrada. É que se pode ver na Fig.7.
O Qui Tollis, duo para contralto e soprano, apresenta variações de andamento de caráter dramático. Inicia em adágio, emprega um trecho em recitativo, volta ao adagio para depois iniciar um andante. Pode-se ver neste último andamento uma série de "malabarismos" vocais (Fig.8 e Fig.9).

Segundo VIEGAS (2004), é francamente perceptível na obra de Santos Cunha a influência de Rossini (17921868). No Cum Sancto Spiritu da Missa Grande o
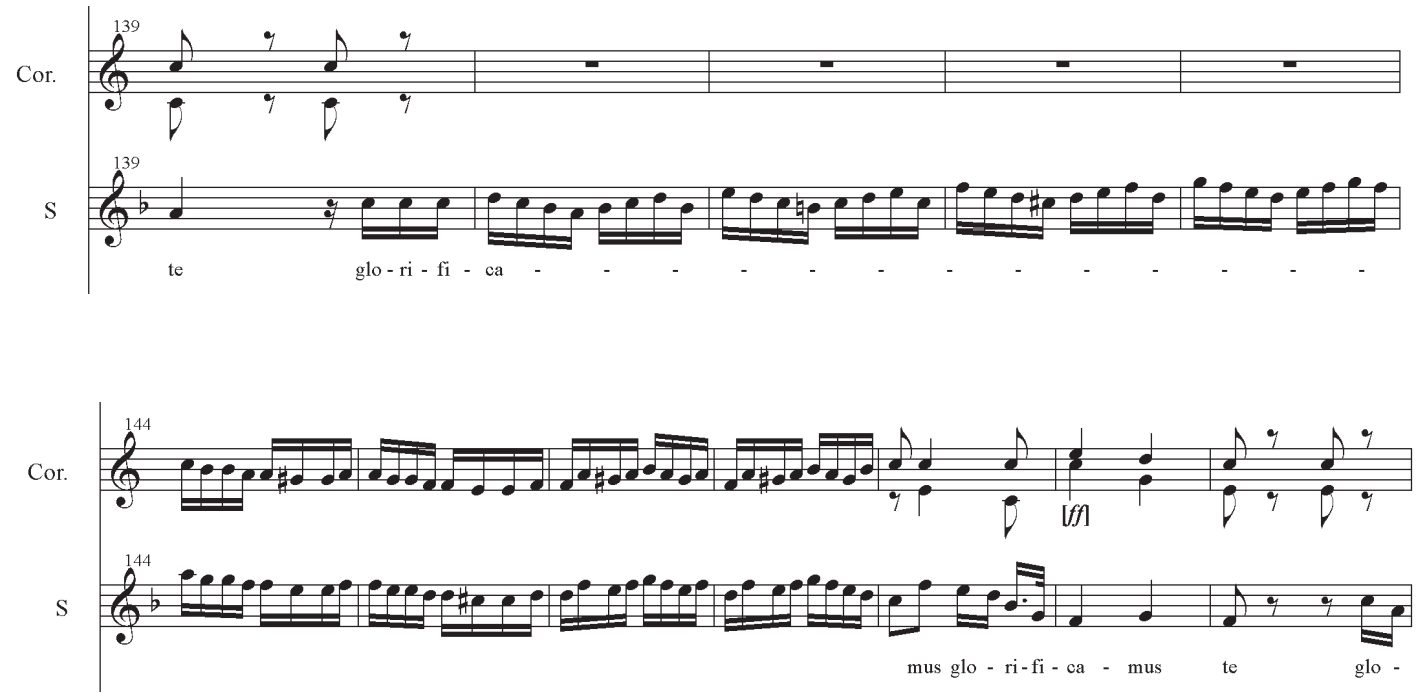

Fig.5: dueto entre trompa e soprano no Laudamus.

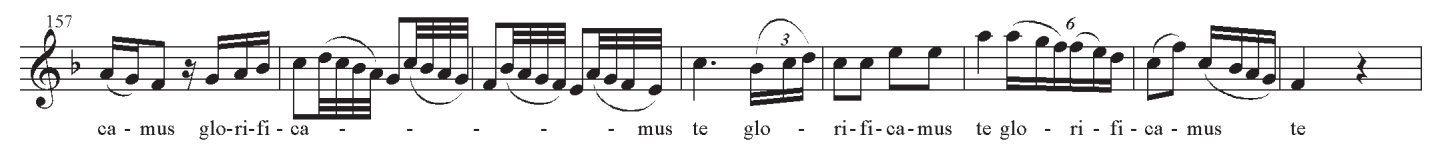

Fig.6: fusas no soprano solo no Laudamus.

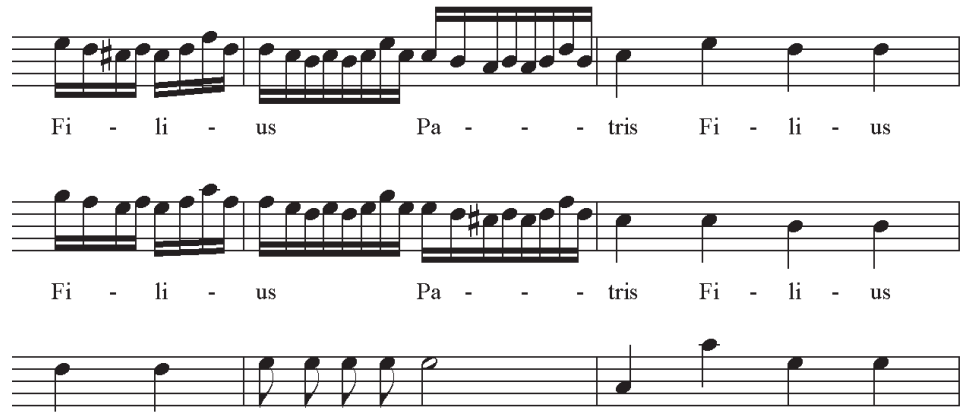

$\mathrm{Fi}-\mathrm{li}-$ us Fi-li-us Pa - - $\quad$ tris $\mathrm{Fi}-\mathrm{li}-$ us

Fig.7: terceto para soprano, tenor e baixo no Domine Deus, c.147-149. 
emprego do baixo orquestral, bem como as cordas, lembram alguns trechos de óperas rossinianas, como a ária La Calúnia do Barbeiro de Sevilha. As Figs.10, 11, 12 e 13, a seguir, mostram trechos para comparação.

\section{5- Considerações finais}

0 reconhecimento das influências operísticas na obra Missa Grande, bem como em outras obras de seu autor, pode ser um importante indicador sobre a melhor performance para as composições de Antônio dos Santos Cunha. Se for levado em conta, que até 0 momento, informações concretas sobre sua vida ainda são muito escassas, os dados oferecidos pelas partituras de sua música tem importância cabal. Aliado ao estudo

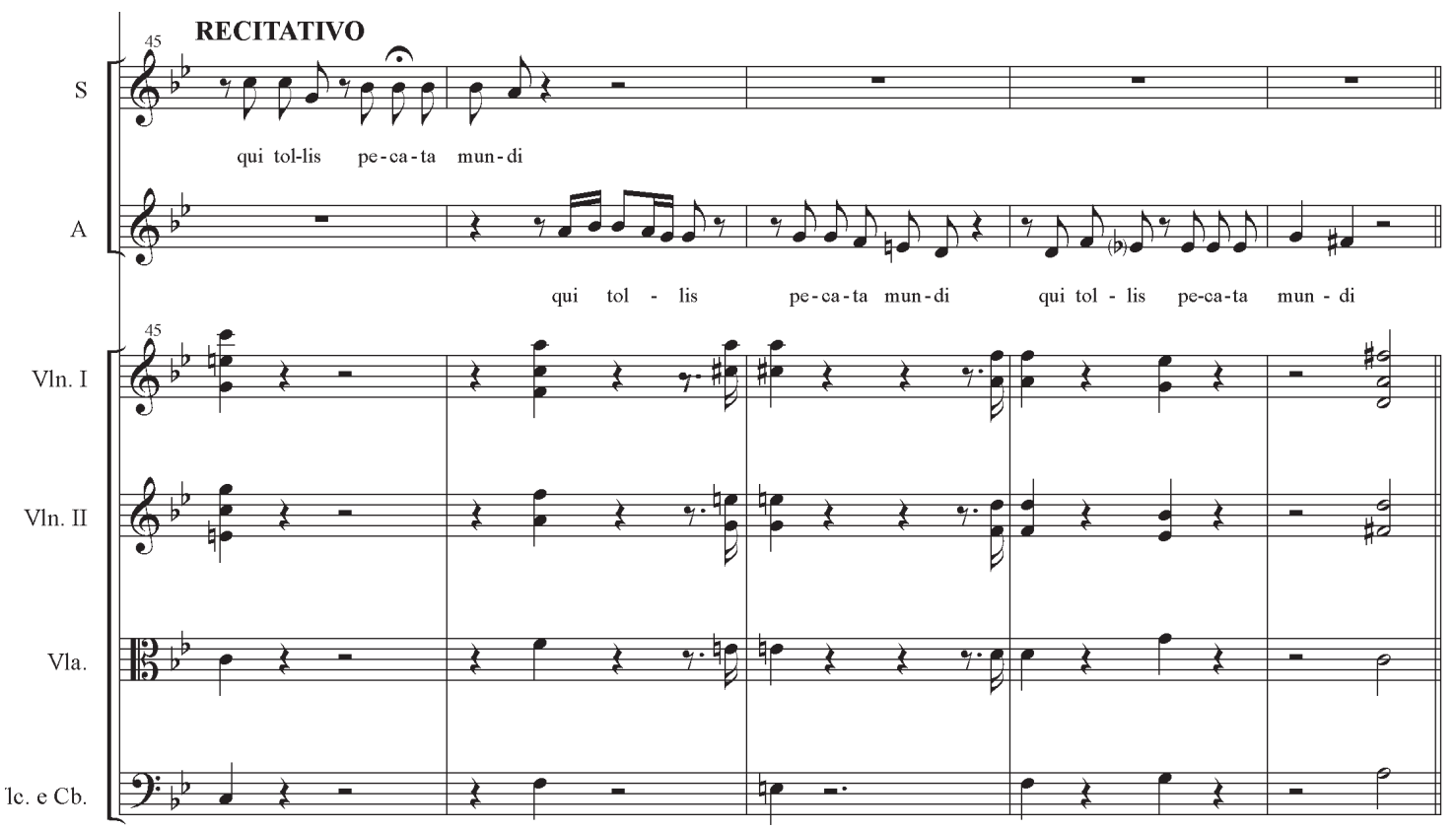

Fig.8: trecho em recitativo do dueto do Qui Tollis.

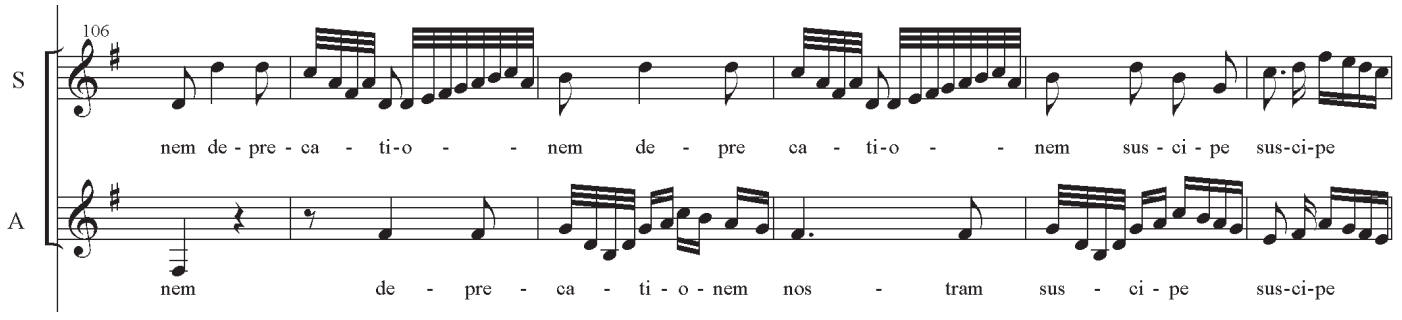

Fig.9: trecho extraído do andante do Qui tollis, onde se podem ver melismas vocais

Vln. I

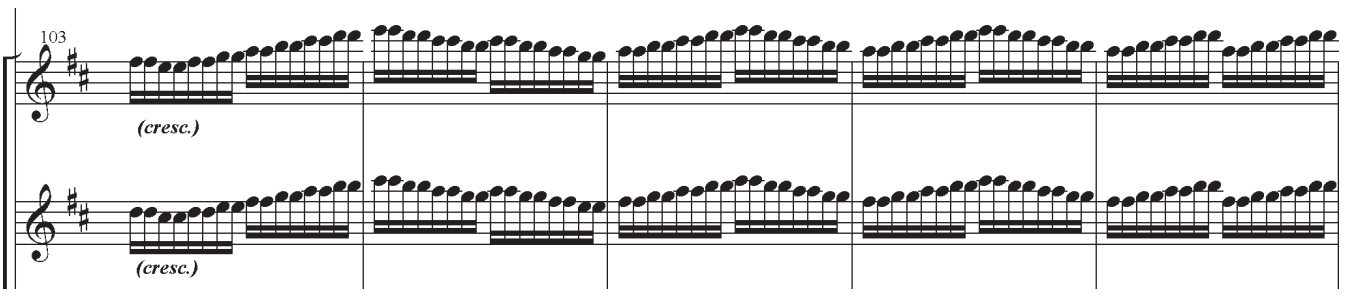

Fig.10: violino I e II do Cum Sancto. 


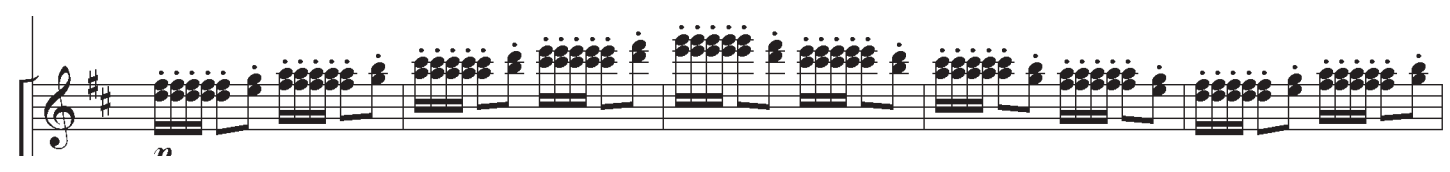

Fig.11: violino I, c.42-46 da ária La calúnia, de Rossini.

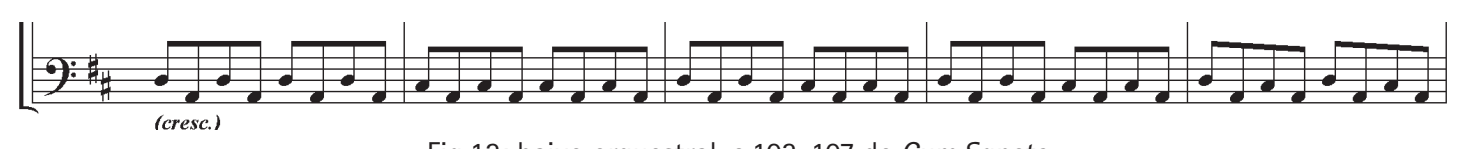

Fig.12: baixo orquestral, c.103-107 do Cum Sancto.

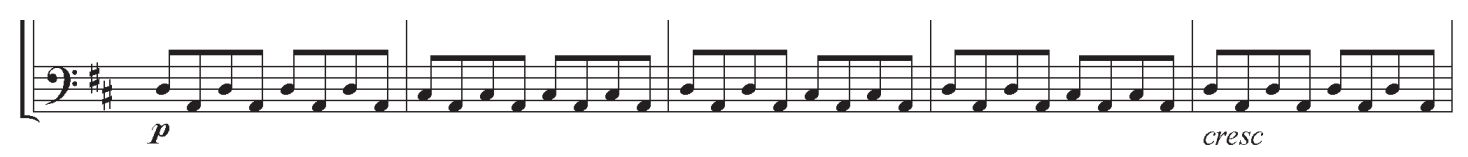

Fig.13: contrabaixo, c.42-46 da ária La calúnia, de Rossini.

de estilo, tais informações são fundamentais para a escolha de práticas interpretativas que possam garantir a compreensão da riqueza musical e franca inventividade deste notável compositor.

\section{Referências}

DIAS, Sérgio. Considerações Sobre a Originalidade da Música Mineira Setecentista in Encontro de
Musicologia: Anais. Paulo Castanha (org.). Rio de Janeiro: Biblioteca Nacional, 2002. 330 p.

KIEFER, Bruno. História da Música Brasileira. Porto Alegre: Movimento, 1977. 138 p.

NEVES, José Maria. (org.) Música Sacra Mineira: biografias, estudos e partituras. $2^{\text {a }}$ ed. Rio de Janeiro: Funarte. 
2000, 359 p.

. A Cultura Mineira no Século XIX (Música) in $3^{\circ}$ Seminário Sobre a Cultura Mineira no Século XIX, do Conselho Estadual de Cultura, MG. Belo Horizonte: Imprensa Oficial, 1982. 228p. NEVES, Stella. São João del-Rei, 03 ago. 2004, 2 fitas cassete (60 min.). Entrevista concedida a Edilson A. Rocha. ROCHA, Edílson. Antônio dos Santos Cunha: conjecturas sobre um notável compositor mineiro. In XVII Encontro da ANPPOM. Anais. São Paulo: ANPPOM. 2007. CD-Rom.

VIEGAS, Aloísio J. São João del-Rei, 16 abr. 2004, 2 fitas cassete (60 min.). Entrevista concedida a Edilson A. Rocha.

Edilson Rocha é mestre em Regência pela UFBA, sob orientação do maestro Erick Magalhães Vasconcelos e também doutorando pela mesma instituição, com previsão de conclusão para 2008. Graduou-se em canto e regência pela UFMG, este último na classe do maestro Sílvio Viegas. Participou de master-classes dos maestros Carlos Alberto Pinto Fonseca, Mögens Dahl, Cláudio Ribeiro, dentre outros. Foi professor em oficinas de regência promovidas pela UFS, UNIMONTES, ambas em MG e UNESP, em SP. Em 2007 atuou como professor contratado pelo Instituto de Artes da UNESP. Foi professor de estruturação musical, canto e regência pelo Conservatório Padre José Maria Xavier, em São João del-Rei, MG. Regeu diversos grupos corais como o Coro de Câmara da EM UFMG, Coral da FALE - UFMG, e orquestrais como Orquestra Cantate, OSUFBA, dentre outras. Têm se dedicado ao estudo, interpretação e divulgação do repertório colonial mineiro. 